Article

\title{
Inventory of Small Forest Areas Using an Unmanned Aerial System
}

\author{
Stefano Puliti *, Hans Ole Ørka, Terje Gobakken and Erik Næsset \\ Department of Ecology and Natural Resource Management, Norwegian University of Life Sciences, \\ PO Box 5003, NO-1432 Ås, Norway; E-Mails: hans-ole.orka@nmbu.no (H.O.Ø.); \\ terje.gobakken@nmbu.no (T.G.); erik.naesset@nmbu.no (E.N.) \\ * Author to whom correspondence should be addressed; E-Mail: stefano.puliti@ nmbu.no; \\ Tel.: +47-649-65800.
}

Academic Editors: Lars T. Waser and Prasad S. Thenkabail

Received: 12 May 2015 / Accepted: 20 July 2015 / Published: 29 July 2015

\begin{abstract}
Acquiring high spatial and temporal resolution imagery from small unmanned aerial systems (sUAS) provides new opportunities for inventorying forests at small scales. Only a few studies have investigated the use of UASs in forest inventories, and the results are inconsistent and incomplete. The present study used three-dimensional (3D) variables derived from UAS imagery in combination with ground reference data to fit linear models for Lorey's mean height $\left(h_{\mathrm{L}}\right)$, dominant height $\left(h_{\mathrm{dom}}\right)$, stem number $(N)$, basal area $(G)$, and stem volume $(V)$. Plot-level cross validation revealed adjusted $\mathrm{R}^{2}$ values of $0.71,0.97,0.60$, 0.60 , and 0.85 for $h_{\mathrm{L}}, h_{\mathrm{dom}}, N, G$, and $V$, respectively, with corresponding RMSE values of $1.4 \mathrm{~m}, 0.7 \mathrm{~m}, 538.2 \mathrm{ha}^{-1}, 4.5 \mathrm{~m}^{2} \cdot \mathrm{ha}^{-1}$, and $38.3 \mathrm{~m}^{3} \cdot \mathrm{ha}^{-1}$. The respective relative RMSE values were $13.3 \%, 3.5 \%, 39.2 \%, 15.4 \%$, and $14.5 \%$ of the mean ground reference values. The mean predicted values did not differ significantly from the reference values. The results revealed that the use of UAS imagery can provide relatively accurate and timely forest inventory information at a local scale. In addition, the present study highlights the practical advantages of UAS-assisted forest inventories, including adaptive planning, high project customization, and rapid implementation, even under challenging weather conditions.
\end{abstract}

Keywords: UAS; forest inventory; area-based approach; structure from motion; photogrammetry 


\section{Introduction}

The recent advent of unmanned aerial systems (UASs) in the civilian market fosters new possibilities to map and estimate forest biophysical properties. High spatial and temporal resolutions represent some of the most important characteristics of data acquired by UASs [1-4]. These aspects, in addition to considerable operational flexibility [5], project customizability, rapidity of data delivery, low cost of imagery acquisition, cloud insensitivity, and shallow learning curve of UAS usage [6], are likely to have a large impact on future studies of forests at fine scales [4] for both commercial and research purposes [5].

\subsection{Background}

As described in Whitehead et al. [5], a UAS typically consists of (1) an unmanned aerial vehicle (UAV); (2) a sensor payload (e.g., laser scanner, digital camera); (3) a navigational computer; (4) a UAV operator, and when necessary; (5) one or more spotters. Such systems have been in use for military purposes for several years, but have only recently become available for civilian purposes [7]. In recent years, the civilian market for UASs has increased rapidly and has become a highly dynamic and diverse market to meet the objectives of a variety of applications. UAVs are generally defined as aircraft with no pilot on board, and the main interest for environmental applications lies in rotor and fixed-wing aircraft equipped with laser, spectral, or thermal sensors to produce three-dimensional (3D) or spectral data [8].

Compared with traditional platforms for the acquisition of remotely sensed (RS) data (e.g., satellites and manned aircraft), UASs are most effective when used to meet the needs of highly accurate surveys over areas in the range of $1-10 \mathrm{~km}^{2}$ [5,9]. UAS environmental applications benefit from a greater operational flexibility due to the possibility of acquiring RS data at precise moments in time under a variety of atmospheric and accessibility conditions [2]. Due to these advantages, rapid growth of the UAS sector is predicted for the next decade [7,10,11].

Retrieving the necessary data to plan silvicultural activities may be one of several relevant areas of UAS applications. Currently, forest inventories in many countries are conducted by adopting an area-based approach (ABA) using a combination of field samples and wall-to-wall airborne laser scanning (ALS) data [12,13]. ALS is cost effective at a large scale, and in some countries (e.g., Norway, Finland), this technique has resulted in coordinated forest inventories that aggregate a multitude of private forest properties. However, in countries where these types of inventories are not carried out, access to accurate data at a small scale becomes too costly. Furthermore, for larger forest properties, timely and accurate data over specific forest areas are needed in the case of more specific pre-harvest, post-harvest, and post-disturbance inventories. Given this context, the main advantage of UASs is the possibility to map areas effectively with very high spatial and temporal resolution, even under cloud cover, because UAS flights are often conducted below the cloud layer. Additionally, relevant cost reductions can be achieved compared with traditional manned airborne remote sensing data acquisitions when the forest inventory areas are small and require a high spatial and/or temporal resolution. The use of UASs in forest inventory research is also of great interest, especially with respect to the finely detailed, multi-temporal component of the data and their potential use in sampling applications [14]. Only a few studies have used UASs for forest inventory purposes [1,4,9], and a review of the main achievements of these studies is lacking in the literature. 


\subsection{UAS Application in Forest Inventories}

The studies where UASs have been used to acquire RS data to map and estimate forest biophysical properties can be classified according to the payload of the UAV. In some of the studies [1], the UASs were equipped with laser scanning sensors (UAS-LS). Often, digital images were acquired and the 3D geometry was generated using software that combined structure from motion (SfM) algorithms and photogrammetric principles (UAS-SfM) [9]. UAS imagery differs from traditional manned airborne imagery that is acquired using user-grade cameras and inexpensive GPSs. The use of user-grade cameras leads to large perspective distortions, poor camera geometry, and a lack of spectral consistency. In addition, the use of inexpensive GPSs and the lack of inertial measurement units lead to poor positioning accuracy. These factors posed challenges in the past with respect to 3D geometry generation from UAS imagery. However, the recent adoption of SfM algorithms in photogrammetric pipelines has made UAS-SfM a suitable tool for forest inventory purposes [4,9]. Compared with traditional digital photogrammetry, for which accurate camera interior and exterior parameters are a prerequisite, SfM algorithms have the advantage of allowing 3D geometry generation from overlapping but otherwise unordered images acquired with uncalibrated cameras.

Most of the published studies have focused on using UAS-LS to map forest biophysical properties from flying above the tree canopy [1,14-17]. However, Chisholm et al. [18] also acquired data below the top of the tree canopy. The main objectives of the studies have been to determine the feasibility of sampling forests remotely without the need of field measurements, to estimate biomass changes over time and to determine whether very high resolution 3D data could improve the accuracy of individual tree crown forest inventories. The high point densities achieved with UAS-LS (i.e., 60-1500 points $\cdot \mathrm{m}^{-2}$ ) proved to yield accurate results when predicting single-tree biophysical properties such as location, stem number, height, diameter at breast height $(\mathrm{DBH})$, crown width, crown base height, biomass change, and rate of pruning. Nevertheless, several factors hamper the operational implementation of UAS-LS and limit their applicability exclusively to research activities [8]. Some of the main limitations are related to the small coverage area, the high cost of the equipment, and the need for specific technical expertise to process the data. The coverage area is restricted by limited battery capacity, the high payload weight, and the need to fly at low altitudes due to the low power of the laser. The high costs of the laser scanners and the carrier phase GPSs make UAS-LS a more expensive solution compared with UAS-SFM. Is also important to mention that UAS-LS rely on a processing phase to produce accurately georeferenced point clouds from the raw laser data. This phase requires specific technical expertise or the acquisition of a license for expensive processing software. Finally, UAS-LS data lack a spectral component, which is provided by UAS-SfM data. It follows that UAS-SfM methods provide a cheaper and more widely available solution for spectral 3D mapping on a larger scale and were therefore selected for the current study.

The development of forest inventory applications using UAS imagery data preceded that of UAS-LS. Nevertheless, the pioneering studies of Aber et al. [19] and Dunford et al. [20] used only the spectral information from the images to classify vegetation. The first example where UAS-SfM was used for the estimation of forest canopy height structure is presented by Dandois and Ellis [21]. The imagery was acquired using a user-grade digital camera (i.e., Canon A470) deployed on a kite over two 2.5 ha plots. An open-source SfM algorithm was used to estimate the internal and external camera parameters and to produce 3D geometries. An ABA was applied to map the dominant height ( $h$ dom) and above ground biomass (AGB) 
in $625 \mathrm{~m}^{2}$ subplots. Measured canopy height was positively correlated with the UAS-SfM point clouds $\left(\mathrm{R}^{2}=0.64\right)$, and the best AGB model had a correlation coefficient $\left(\mathrm{R}^{2}\right)$ of 0.52 and a relative RMSE of 53\%. The results achieved with the point clouds derived from the SfM algorithms were poorer than the results obtained using ALS. Nevertheless, the study envisioned the importance of the use of dense 3D data derived from UAS imagery to model forest biophysical properties and noted the strengths and flaws of such systems.

Since the early experiences in the use of UAS to acquire imagery over forests using kites or other platforms, there has been a rapid development of robotic, computer vision, and geomatic technologies [2,22]. Such development is currently ongoing and due to increased accessibility, users are currently able to use complex UAS-SfM methods to meet the goals of highly accurate 3D forest surveys. The first examples of applying advanced UAS-SfM methods are represented by Wang et al. [23] and Gini et al. [24], who described the systems used, the data acquisition process, and the algorithms implemented. Fritz et al. [25] used oblique UAS imagery in SfM pipelines to reconstruct tree stems in open stands. A first attempt to model forest biophysical properties by means of UAS-SfM data was presented by Dandois and Ellis [9], who used a hobbyist-grade UAS integrated with a digital camera for multi-temporal 3D and spectral data acquisition over a deciduous forest. In their study, the objective was to use UAS-SfM point clouds to model $h_{\text {dom }}\left(\mathrm{R}^{2} 0.07-0.84\right)$, AGB $\left(\mathrm{R}^{2} 0.27-0.73\right)$, and changes in canopy spectral properties in relation to MODIS NDVI ( $\mathrm{R}^{2} 0.87$ ). The large differences in terms of $\mathrm{R}^{2}$ and accuracy across the three study sites did not allow a clear evaluation of the operational applicability of such methods for forest inventories. Lisein et al. [4] opted for a UAS-SfM fixed-wing solution to acquire imagery across a forest landscape (200 ha). The open source software MICMAC [26] was used to generate a 3D point cloud from overlapping Gatewing X100 imagery [27]. The fixed-wing platform was preferred to a multirotor UAV for the ability of covering larger areas $[2,4]$. An ABA was used to model $h_{\text {dom, and an individual }}$ tree crown approach was used for single-tree height. The ABA results showed adjusted $\mathrm{R}^{2}, \mathrm{RMSE}$, and relative RMSE values of $0.82,1.65 \mathrm{~m}$, and $8.4 \%$, respectively. For the individual tree crown approach, the results were slightly better, with adjusted $\mathrm{R}^{2}$, RMSE, and relative RMSE values of $0.91,1.04 \mathrm{~m}$, and $4.7 \%$, respectively. The study provided only a glimpse of the potential of UAS-SfM data to map forest biophysical properties, while the main objective was to describe the photogrammetric workflow. In addition, the study was conducted using varying plot areas, which does not represent an optimal sampling strategy when carrying out ABA forest inventories due to potential bias introduced in the predictions because of the scale-dependent issues demonstrated in inventories carried out using ALS [28]. The use of UAS photogrammetric point clouds for the individual tree crown approach was also tested by Sperlich et al. [29]. In a coniferous site, these authors were able to detect $87.7 \%-90.3 \%$ of the trees and predict the mean height with an accuracy of $0.5 \mathrm{~m}$. While the results of the abovementioned pioneering studies are encouraging, they are inconsistent and not exhaustive, and therefore seem insufficient for recommendations for the operational application of such methods.

It follows that further understanding of UAS-SfM is needed as these systems are in their early development phase and several error sources may affect their operational applicability. In fact, intrinsic issues related to the use of UAS-SfM in forest environments might affect the quality of the final outputs. The generation of 3D geometries at low flight altitudes due to UAS regulations is affected by several problems. Compared with other types of UAS-SfM applications, forest surveys are particularly affected by high relief displacement [2], the presence of moving objects (swinging tree tops, shade), and pronounced distortion due to perspective shown as trees leaning towards the sides of the image [4]. Other 
UAS-SfM limitations relate to the UAV hardware, which usually consists of user-grade equipment, resulting in poor geotagging of the imagery as well as poor image quality in terms of both spectral and geometrical properties [2]. It is therefore crucial to quantify the errors associated with the use of UAS-SfM for small-scale forest inventories and thereby determine the applicability of such technology.

\subsection{Objectives}

To the authors' knowledge, no study has evaluated the potential of UAS-SfM data to model a variety of forest biophysical properties in conifer-dominated boreal forests. However, airborne photogrammetric data has proven to be a viable data source alternative to ALS to model forest biophysical properties [30,31], suggesting the possibility to apply such methods to UAS-SfM data. Thus, the objectives of our study were to:

- Assess the accuracy of Lore's mean height $\left(h_{\mathrm{L}}\right), h_{\text {dom, stem number }}(N)$, basal area $(G)$, and stem volume $(V)$ determined with an ABA combining UAS-SfM and field data in a small forest property (200 ha) in Norway.

- Evaluate the importance of using spectral information in modeling the abovementioned properties.

\section{Study Area and Materials}

\subsection{Study Area}

The study was conducted in a 194.7-ha boreal forest area in Våler municipality $\left(59^{\circ} 30^{\prime} \mathrm{N}, 10^{\circ} 55^{\prime} \mathrm{E}\right.$, 70-120 $\mathrm{m}$ above sea level) located in south-eastern Norway (Figure 1). The area is part of a larger forest area (852.6 ha) inventoried using ALS in 1999 and 2010. The smaller area was selected as it constituted a single private property and was therefore an example of a medium- to small-sized forest property in Norway for which UAS may be effectively used for forest inventory purposes. The dominant tree species is Norway spruce (Picea abies (L.) Karst.), followed by Scots pine (Pinus sylvestris L.), and deciduous trees dominated by birch (Betula pubescens Ehrh.). The percentage of each species in terms of basal area is $52 \%, 37 \%$, and $11 \%$ for spruce, pine, and deciduous trees, respectively. The forest is mainly managed for timber production. Silvicultural treatments are carried out according to established best practices in boreal forests in Norway. These include clear-felling and shelterwood cutting systems depending on the site productivity. On more fertile sites, clear cutting is usually applied followed by planting, whereas in pine-dominated stands on poorer sites, the shelterwood cut system is preferred in combination with planting or natural regeneration.

\subsection{Field Measurements}

A field campaign was conducted during nine days in July 2014. Field measurements were conducted in 38 circular fixed-area sample plots $\left(400 \mathrm{~m}^{2}\right)$. The sample plots were selected from a larger set of permanent plots systematically distributed throughout the study area according to a regular grid. The plot data were collected by measuring the $\mathrm{DBH}$ for all trees with $\mathrm{DBH} \geq 4 \mathrm{~cm}$. Sample trees for height measurements were selected based on a probability proportional to stem basal area and measured using a Vertex hypsometer. The errors that can be expected in the height measurements are in the order of 
$2 \%-5 \%$ of the tree height $[32,33]$. For trees without height measurements, height was predicted using height-DBH models devised by Fitje and Vestjordet [34] and Vestjordet [35]. The volume of each sample tree was predicted using species-specific volume models using DBH and either measured or predicted height as predictor variables [36-38]. The reported errors for the volume models were approximately $10 \%$ of the measured volume [38]. The volume estimates were then adjusted by the species-specific ratio of the mean volume estimate for trees with predicted heights and those with measured heights. Species-specific ground reference volume was computed as the sum of the volume of each individual tree by species.
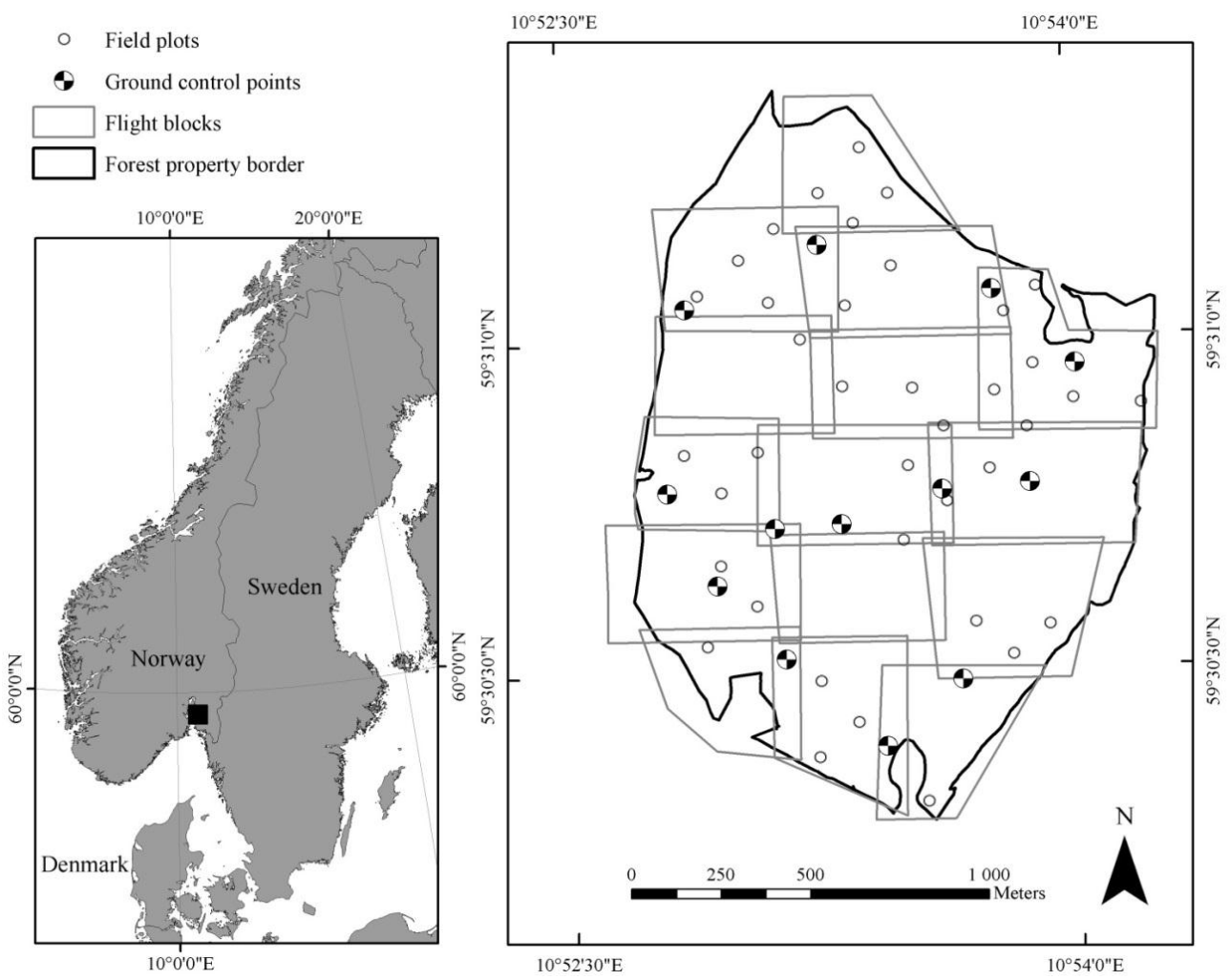

Figure 1. Project overview with field plots and ground control point locations. The flight blocks show how the imagery data were collected according to the office-planning phase.

Table 1. Summary of the field data ${ }^{\text {a }}$.

\begin{tabular}{ccc}
\hline Property & Range & Mean \\
\hline$h_{\mathrm{L}}(\mathrm{m})$ & $6.7-17.1$ & 11.4 \\
$h_{\mathrm{dom}}(\mathrm{m})$ & $13.1-28.4$ & 19.8 \\
$N\left(\mathrm{n} \cdot \mathrm{ha}^{-1}\right)$ & $350.0-3625$ & 1372 \\
$G\left(\mathrm{~m}^{2} \cdot \mathrm{ha}^{-1}\right)$ & $19.7-43.8$ & 29.2 \\
$V\left(\mathrm{~m}^{3} \cdot \mathrm{ha}^{-1}\right)$ & $136.6-580.9$ & 256.1 \\
\hline
\end{tabular}

${ }^{\text {a }} h_{L}=$ Lorey's mean height, $h_{\mathrm{dom}}=$ dominant height, $N=$ stem number, $G=$ basal area, $V=$ volume.

The present study considered the following forest classes: young and mature on poor sites, and mature on fertile sites. The height above sea level ranged from $38 \mathrm{~m}$ to $112 \mathrm{~m}$ and was on average $84 \mathrm{~m}$. The slope ranged from $3^{\circ}$ to $21^{\circ}$ with an average of $10^{\circ}$. Most of the plots faced south or south west. A summary of the field data is presented in Table 1. 


\subsection{Remotely Sensed Data}

The remotely sensed data consisted of ALS and UAS imagery datasets. The ALS data were acquired under leaf-on conditions on 2 July 2010 using an Optech ALTM-Gemini laser scanner mounted on a Piper Navajo fixed-wing aircraft and resulted in an average pulse density of 7.45 points $\cdot \mathrm{m}^{-2}$. The pre-processing of the ALS data was carried out by the contractor (Blom Geomatics, Norway). This included the computation of planimetric coordinates, ellipsoid height values, and point cloud classification into ground and non-ground echoes according to the proprietary algorithm implemented in Terrascan software [39]. A triangulated irregular network (TIN) surface was then created by linear interpolation from the ground-classified points.

UAS imagery was collected during five days between 27 November and 3 December 2014. The acquisition was conducted during late fall due to time constraints. The specific time of the year was not optimal for imagery acquisition in terms of image quality due to the poor spectral response of the vegetation caused by the absence of vegetative activity in the canopy and the presence of snow. Also, the efficiency of the UAS data acquisition was poor because of the cold temperatures reducing battery life, and the reduced time available for image acquisition during this time of the year at northern latitudes. In the present study, a SenseFly eBee fixed-wing UAV [40] was used for the remotely sensed data acquisition. The UAV weighs approximately $537 \mathrm{~g}$ without payload and has a maximum flight time of 45 minutes under optimal weather conditions. The eBee is equipped with an onboard global navigation satellite system (GNSS) to provide rough positioning. For this study, the eBee was equipped with a Canon S110 near infra-red (NIR) camera as the payload. The camera size is $7.44 \times 5.58 \mathrm{~mm}$, weighs approximately $153 \mathrm{~g}$ without a battery, and has focal length of $24 \mathrm{~mm}$. The sensor produces three 12.1-megapixel images in the green $(550 \mathrm{~nm})$, red $(625 \mathrm{~nm})$, and NIR $(850 \mathrm{~nm})$ wavelengths. The camera was chosen as spectrally suitable for vegetation surveys. The camera was set with the SenseFly predefined camera settings [41], with shutter speed of 1/2000 sec and aperture and ISO adapting to the light conditions of every shot. These settings ensured the best exposure, and prevented the images from being affected by motion. The resulting images were stored in jpeg format, with an image size of $4000 \times 3000$ pixels and an aspect ratio of $4: 3$. The estimated ground sampling distance at $120 \mathrm{~m}$ above ground level was $0.042 \mathrm{~m}$, resulting in an estimated field of view of $168 \times 126 \mathrm{~m}$. The camera was triggered automatically based on a predefined flight plan, with a minimum interval between two consecutive images of approximately 5 seconds. This interval was longer than what was expected and was caused by the eBee's flight pattern (personal communication with senseFly support). In fact, to ensure image stability, the UAV ascends, turns off the engine, and captures the images in the descent. This flight maneuver required approximately 5 seconds; however, the time interval was reduced by one second in later firmware updates [42].

\section{Methods}

\subsection{UAS Imagery Collection-Planning and Implementation}

The imagery acquisition started with an office-planning phase to determine the main flight parameters. For this phase, the flight planning and monitoring software eMotion 2 version 2.4.2 [40] and Quantum GIS software [43] were used. Once the area to survey was located, eMotion was used to simulate the flight 
missions to obtain an idea of how these were going to be implemented in the field. Some of the main input parameters required in the planning were flying altitude, working area radius, and image overlap. Norwegian national aviation regulations required the UAS operations to be conducted within visual line of sight (VLOS), meaning that each flight had to be executed in a way that the aircraft could be observed by the naked eye at all times. A maximum flying altitude of $125 \mathrm{~m}$ above ground level and a working area radius of maximum $600 \mathrm{~m}$ defined the VLOS. The overlap was set to $95 \%$ longitudinal and $80 \%$ lateral. In addition, the flights were planned with perpendicular flight lines. Such redundancy of flight lines was required due to the long camera triggering interval, resulting in small longitudinal overlaps. Initial tests showed unsatisfactory results with lower overlaps over forest areas. However, it is important to mention that the defined nominal longitudinal overlap was only indicative, being subject to changes in the actual flight due to wind and differences between the simulated and actual flight (i.e., longer time between consecutive images in real flights). These limitations led to the planning of 15 flight blocks to achieve wall-to-wall coverage of the study area (Figure 1). The flight altitude was set to $120 \mathrm{~m}$ to ensure that the legal maximum flight height was respected, resulting in an effective ground sampling distance of $0.035 \mathrm{~m}$ and a base to height ratio of 0.43 . Based on the 15 flight blocks and existing aerial imagery, the home points (take-off and landing points) and ground control points (GCPs) were located in the available open areas (e.g., clear-cuts, agricultural fields). GCPs were marked points on the ground used to georeference the output 3D model from the photogrammetric processing of the UAS imagery. In total, 13 GCPs were distributed subjectively based on a uniformity criterion (Figure 1).

The field phase began with marking the GCPs on the ground and measuring their position. The GCPs consisted of $50 \times 50$-cm targets with a black and white checkerboard pattern to ensure the largest contrast in the images. The targets were fixed to the ground and differential global positioning systems (GPSs) and global navigation satellite systems (GLONASSs) were used to determine the position of the center of each GCP. The base station was located at the closest official reference point of the Norwegian Mapping Authority. A Topcon Legacy-E+ 40 channel dual-frequency receiver observing the pseudorange and carrier phase of both GPS and GLONASS was used to measure the center position of the target. Data collection lasted for approximately $15 \mathrm{~min}$ for each GCP with a 2 -sec logging rate. After returning to the office, the recorded coordinates were post-processed with correction data from the base station using Pinnacle software [44]. The post-processed GCP coordinates revealed standard deviations for northing, easting, and height of $0.7 \mathrm{~cm}, 0.5 \mathrm{~cm}$, and $1.4 \mathrm{~cm}$, respectively. After the position of the GCPs was measured, the flights missions were carried out. The time of year, weather and battery capacity (UAV and laptop) were limiting factors, which allowed the completion of a maximum of four missions per day. The weather was rather stable during the five days of imagery collection, with full cloud cover for most of the flights, and occasional precipitation in the form of snow. On the last day, fog was present during the first flight and sun during the second one. The wind speed ranged from 2 to $7 \mathrm{~m} \cdot \mathrm{sec}^{-1}$, and the temperature was approximately $0{ }^{\circ} \mathrm{C}$. The flights lasted an average of approximately 24 minutes, and the coverage of each flight was 16.2 ha on average. Following the landing of the UAV, the images were downloaded to the field laptop and processed with eMotion Flight Data Manager. A total of 3250 images were acquired and exported as geotagged JPEG files with a total size of 10.5 GB. As shown in Figure 2, several issues affected the image quality, such as different light and atmospheric conditions in different flights, saturation, blurriness, the presence of snow on part of the canopy, and the presence of snowflakes 
and/or fog in parts of the images. The actual longitudinal overlap was approximately $50 \%$. A summary of the flight characteristics is presented in Table 2.
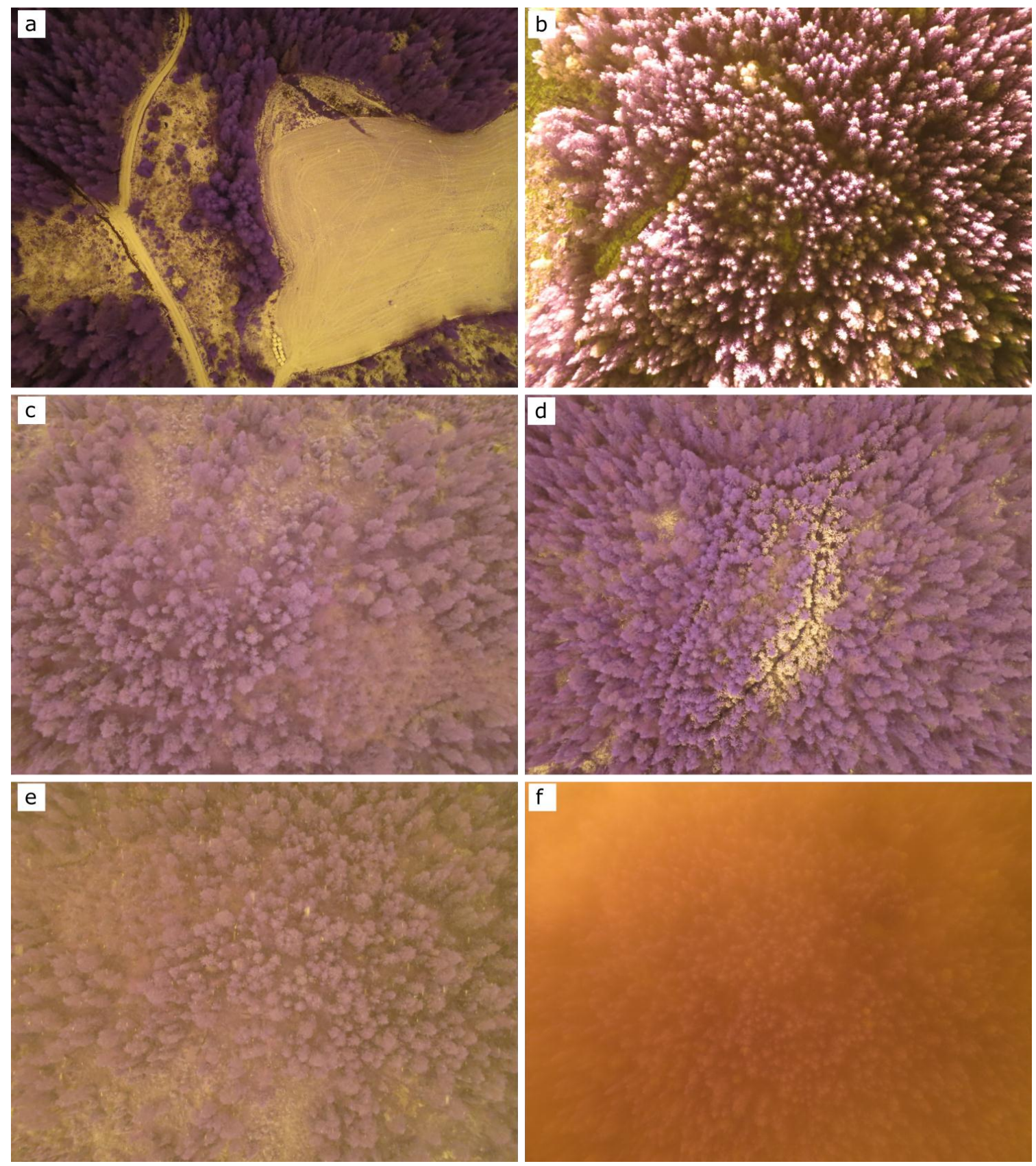

Figure 2. Factors affecting image quality. In general, is possible to see that the imagery was characterized by large perspective distortions and different light and atmospheric conditions in different flights. In particular: (a) saturation due to the high scene contrast causing the forest to look dark; (b) during the sunny flight, the tree tops were saturated due to illumination of only the tree tops enhanced by the low sun angle; (c) blurriness caused by high wind speed $\left(7 \mathrm{~m} \cdot \mathrm{sec}^{-1}\right)$; (d) presence of snow on some parts of the canopy causing these parts to have an anomalous spectral response with regard to the object represented; (e) presence of snowflakes in the images due to precipitation during image acquisition; (f) presence of fog during image acquisition, which reduced the visibility and sharpness of the image. 
Table 2. Summary of flight characteristics for each flight block of imagery collection.

\begin{tabular}{|c|c|c|c|c|c|c|c|}
\hline Date & Flight\#. & $\begin{array}{l}\text { No. of } \\
\text { Images }\end{array}$ & $\begin{array}{l}\text { Flight Time } \\
\text { (min) }\end{array}$ & $\begin{array}{c}\text { Coverage } \\
\text { (ha) }\end{array}$ & $\begin{array}{l}\text { Size } \\
(\mathrm{MB})\end{array}$ & $\begin{array}{c}\text { Wind-Speed } \\
\left(\mathbf{m} \cdot \sec ^{-1}\right)\end{array}$ & Weather \\
\hline 27.11 .14 & 1 & 247 & 26 & 17.2 & 678 & $6-7$ & Full cloud cover + snow \\
\hline \multirow{4}{*}{ 29.11.14 } & 2 & 223 & 24 & 19.7 & 734 & $4-5$ & \multirow{4}{*}{ Full cloud cover } \\
\hline & 3 & 252 & 27 & 17.5 & 832 & & \\
\hline & 4 & 197 & 23 & 14.6 & 654 & & \\
\hline & 5 & 186 & 23 & 15.7 & 613 & & \\
\hline \multirow{4}{*}{30.11 .14} & 6 & 194 & 23 & 14.4 & 636 & $4-5$ & \multirow{4}{*}{ Full cloud cover } \\
\hline & 7 & 226 & 25 & 14.2 & 742 & & \\
\hline & 8 & 227 & 25 & 17.1 & 775 & & \\
\hline & 9 & 237 & 26 & 17.2 & 825 & & \\
\hline \multirow{4}{*}{02.12 .14} & 10 & 220 & 24 & 18.2 & 686 & $3-5$ & \multirow{4}{*}{ Full cloud cover + snow } \\
\hline & 11 & 223 & 24 & 17.3 & 677 & & \\
\hline & 12 & 231 & 25 & 16.4 & 774 & & \\
\hline & 13 & 184 & 21 & 12.5 & 613 & & \\
\hline \multirow{2}{*}{03.12 .14} & 14 & 218 & 24 & 17.6 & 526 & $2-5$ & Fog \\
\hline & 15 & 185 & 21 & 13.1 & 711 & & Sun \\
\hline TOTAL & 15 & 3250 & 361 & 242.7 & 10476 & & \\
\hline
\end{tabular}

\subsection{Photogrammetric Processing}

The present study used the proprietary software Agisoft Photoscan Professional Edition 1.1.0 (64 bit) [45] to generate 3D dense point clouds from the entire set of images. The software was chosen as it has been proven to be effective in the production of dense and accurate point clouds over forest areas [9]. Photoscan offers a user-friendly processing pipeline that combines proprietary algorithms from computer vision SfM and stereo-matching algorithms to accomplish the tasks of image alignment and multiview stereo-reconstruction [46]. In our study, an intermediate step of camera alignment optimization was carried out using accurately measured GCPs. The steps involved in Photoscan's pipeline and their relative parameterization are presented in Table 3. These parameters were chosen either by following Agisoft online tutorials [47] or by using a trial and error approach to identify those producing the best results and to allow the processing of the entire set of images as a single block.

Image alignment consisted of the sparse reconstruction of 3D geometry by detecting and matching image feature points in overlapping images using SfM techniques. The estimation and optimization of the camera orientation and internal parameters are the main outputs of this stage. Consequently, GCPs were used to improve the estimates of camera position and orientation, allowing for more accurate model reconstruction. Their coordinates were imported and placed using a guided approach. Photoscan projected the ray corresponding to each GCP onto a coarsely reconstructed mesh and selected the images in which each GCP was visible. Consequently, their positioning was manually refined. Camera alignment was then optimized based on the GCPs. The difference between the input camera and GCP positions and the Photoscan-estimated ones revealed average RMSEs of $3.7 \mathrm{~m}$ and $0.006 \mathrm{~m}$, respectively. The error in camera positioning was largely attributable to the height positioning error. Point cloud densification was performed to increase the level of detail using multiview stereo-reconstruction algorithms at a pixel level. A medium quality was selected to reduce excessive processing time. This 
meant that the image size was downscaled by a factor of 8 compared with the original images. Point cloud outliers were removed using mild depth filtering as it simultaneously reduced noise and allowed for the most height variation between the 3D points, resulting in the most suitable parameterization in forestry applications. The resulting dense point cloud was exported to an ASCII file, with $\mathrm{x}, \mathrm{y}$, and $\mathrm{z}$ coordinates with red, green, and near-infrared (XYZ-RGNIR) information. A proprietary algorithm from Photoscan was used to assign digital number (DN) values from the RGNIR images to the point cloud. Photoscan was installed on a dual Intel® Xeon® X5650 workstation $(2 \times 6$ CPU cores $)$ with 64 GB of RAM, which required 30 hours of continuous computation to complete the generation of the point cloud across the study site.

The absolute heights of the point cloud were normalized to obtain relative heights by subtracting the terrain height from the ALS TIN model from the height value of each point. The point cloud spectral data were radiometrically corrected by dividing the $\mathrm{DN}$ of each band (i.e., red, green, NIR) by the sum of the DN values of all of the bands corresponding to the same 3D point. This method was used as it was proven to improve the accuracy in species classification by reducing the differences in radiance among different images [48-51]. An overview of the processed data is provided in Figure 3. The orthophoto mosaic is shown exclusively for visualization purposes as it was not used in the present study. Additionally, Figure 3 shows a transect representing the UAS-SfM point cloud and the corresponding ground returns from the ALS dataset.

Table 3. Processing steps with corresponding parameters in Photoscan's pipeline for the generation of 3D point clouds from UAS imagery.

\begin{tabular}{|c|c|}
\hline Task & Parameter \\
\hline \multirow{4}{*}{ Align photos } & Accuracy: high ${ }^{\mathrm{b}}$ \\
\hline & Pair selection: reference ${ }^{b}$ \\
\hline & Key point limit: $40000^{\mathrm{b}}$ \\
\hline & Tie point limit: $1000^{\mathrm{b}}$ \\
\hline \multirow{5}{*}{ Build mesh } & Surface type: height field ${ }^{b}$ \\
\hline & Source data: sparse \\
\hline & point cloud ${ }^{\mathrm{b}}$ \\
\hline & Facecount: low (13544) ${ }^{a}$ \\
\hline & Interpolation: enabled ${ }^{\mathrm{b}}$ \\
\hline \multicolumn{2}{|l|}{ Guided marker positioning } \\
\hline \multirow{7}{*}{ Optimize camera alignment } & Marker accuracy (m): \\
\hline & $0.005^{\mathrm{b}}$ \\
\hline & Projection accuracy \\
\hline & (pix): $0.1^{\mathrm{b}}$ \\
\hline & Tie point accuracy (pix): $4^{\mathrm{b}}$ \\
\hline & Fit all except for $\mathrm{k} 4^{\mathrm{b}}$ \\
\hline & Number of GCPs: $13^{\mathrm{a}}$ \\
\hline \multirow{2}{*}{ Build dense cloud } & Quality: Medium $^{\text {a }}$ \\
\hline & Depth filtering: mild ${ }^{\text {a }}$ \\
\hline
\end{tabular}

${ }^{\mathrm{a}}$ parameters chosen using the trial and error approach; ${ }^{\mathrm{b}}$ parameters suggested in online tutorials 

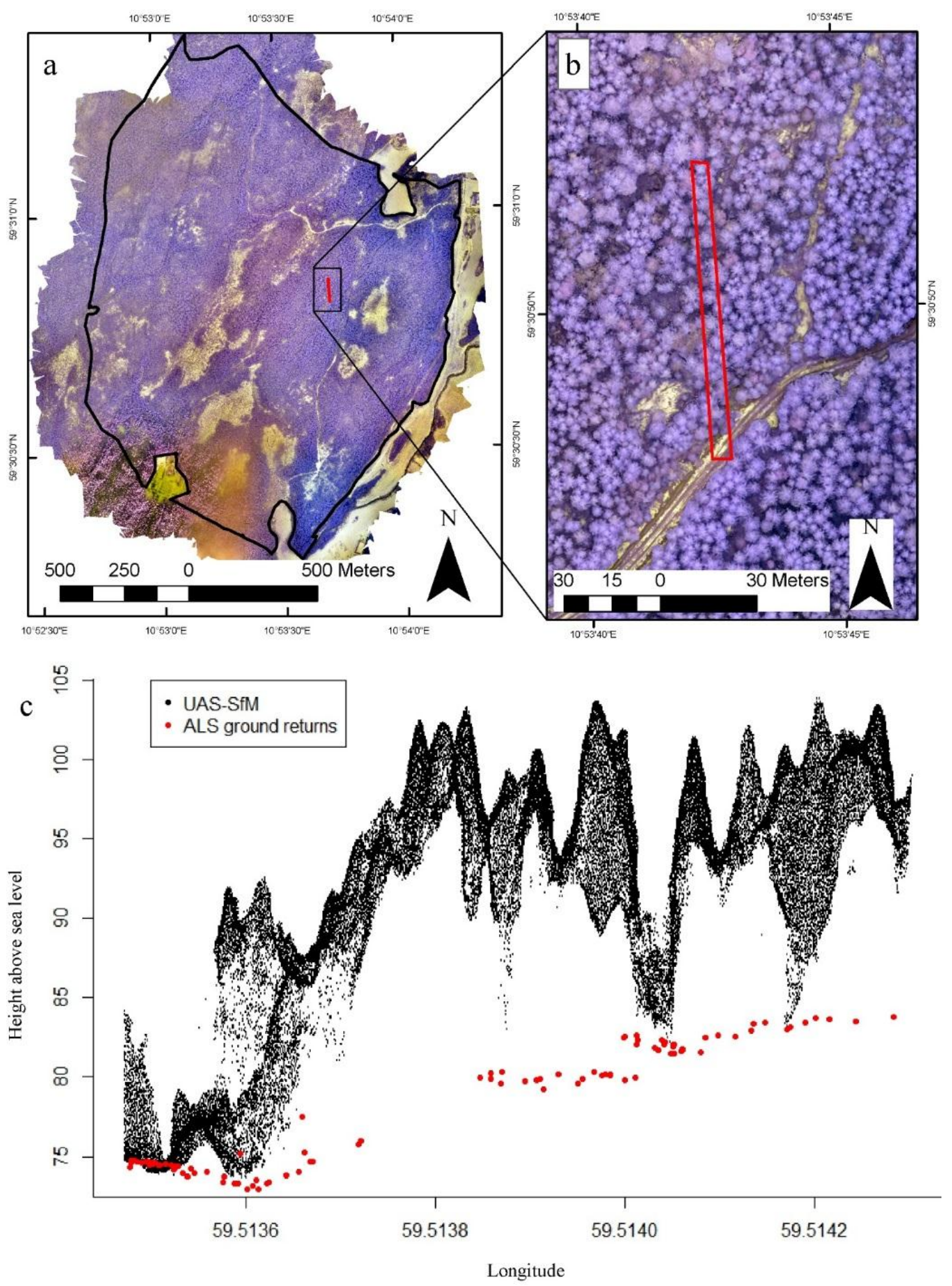

Figure 3. Overview of the data used in the study. (a) Orthophoto mosaic of the total inventory area shown only for visualization purposes; (b) detail of the orthophoto mosaic showing the high resolution of the imagery, including the transect; (c) transect showing the vertical distribution of the UAS-SfM point cloud (in black) and the corresponding ALS ground returns (in red). 


\subsection{Variable Extraction and Statistical Methods}

A total of 21 structural independent variables were computed for each field plot. These included height percentiles $\left(p_{10}, \ldots, p_{100}\right)$, height standard deviation $\left(h_{\mathrm{sd}}\right)$, and density variables [52]. The latter data were calculated for equally spaced vertical layers, defined as tenths of the distance between the $95^{\text {th }}$ percentile and the lowest canopy height (i.e., $2 \mathrm{~m}$ ). The densities were computed as the proportion of points above the 1 st $, \ldots, 9$ th $(d o, \ldots, d 9)$ fraction to the total number of points. In addition, nine spectral variables were extracted for each plot. These included mean band values $\left(R_{\mathrm{m}}, G_{\mathrm{m}}\right.$, and $\left.N I R_{\mathrm{m}}\right)$, band standard deviations ( $R_{\mathrm{sd}}, G_{\mathrm{sd}}$, and $\left.N I R_{\mathrm{sd}}\right)$, and band ratios ( $R_{\text {red/green }}, R_{\mathrm{red} / \mathrm{NIR}}$, and $\left.R_{\text {green/NIR }}\right)$. A 2-m height threshold was applied to filter out the canopy component from the low vegetation $[53,54]$.

The independent variables were related to the field data using multiple regression analysis and the estimated parameters were used to predict the biophysical properties of interest (i.e., $h_{\mathrm{L}}, h_{\mathrm{dom}}, N, G$, and $V$ ). Logarithmic transformations of the dependent variable were used exclusively for $h \mathrm{~L}, N$, and $V$ as this has previously been shown to be suitable for the modeling of these properties [31,54]. To reduce the dimensionality of the independent variables and avoid problems of collinearity, variable selection was carried out. For each dependent variable of interest, ordinary linear regression models were fitted. A branch-and-bound search for the best subset was carried out using the R-package leaps [55]. The search was restricted to models with a maximum of five variables. The model selection was performed using the Bayesian information criterion. Furthermore, the selection procedure was penalized for collinearity using the variance inflation factor. The subset with one variable less was iteratively selected if any of the variables in the current subset had a variance inflation factor $\geq 5$. For the models using the logarithmic transformation of the dependent variable, the predictions were converted to arithmetic scale using the exponential function and multiplied by a bias correction factor. As proposed by Snowdon [56], the bias correction factor for the logarithmic regression was derived empirically as the ratio of the mean of the observed values to the mean of the back-transformed predicted values. The adjusted $R^{2}\left(\operatorname{adj} . R^{2}\right.$ ) was used to evaluate the goodness of fit of the models. To address the advantage of UAS-SfM for also retrieving spectral data, models were developed even without the spectral information, and the results were compared with models that included all of the independent variables. t-Student, Shapiro-Wilk, and Breusch-Pagan tests were performed, respectively, to determine whether the error term had a mean equal to zero, if it was normally distributed, and if its variance was constant.

The accuracy of the predictions was validated at a plot level using leave-one-out cross-validation (CV). For each biophysical property of interest, the selected independent variables were used to fit the models to the field data by iteratively leaving one observation out at a time. The estimated parameters were then used to predict each variable of interest for the remaining observation. The root mean square error (RMSE) and mean difference $(\bar{D})$ were determined for each plot using the following equations:

$$
\begin{aligned}
\text { RMSE } & =\sqrt{\frac{\sum_{i=1}^{n}\left(y_{i}-\hat{y}_{i}\right)^{2}}{n}} \\
\overline{\mathrm{D}} & =\frac{\sum_{i=1}^{n}\left(y_{i}-\hat{y}_{i}\right)}{n}
\end{aligned}
$$

where $n$ is the number of field plots; $y_{i}$ is the ground reference value for $h_{\mathrm{L}}, h_{\mathrm{dom}}, N, G$, or $V$ for plot $i$; and $\hat{y}_{i}$ is the predicted value for the same plot. The relative RMSE and relative mean difference were calculated as the percentage of the mean ground reference value. The significance of the differences 
between the mean CV predicted and reference values was tested using a two-sided t-test at a 95\% confidence level.

\section{Results}

\subsection{Regression Modeling}

The biophysical properties of interest in the 38 sample plots were regressed against the predictor variables computed from the point cloud. According to the implemented variable selection method, all of the models comprised a maximum of four explanatory variables (Table 4). The adj. $\mathrm{R}^{2}$ values for $h_{\mathrm{L}}$, $h_{\mathrm{dom}}, N, G$, and $V$ were $0.71,0.97,0.60,0.60$, and 0.85 , respectively.

Table 4. Summary of the regression analysis for Lorey's mean height $\left(h_{\mathrm{L}}\right)$, dominant height $\left(h_{\text {dom }}\right)$, stem number $(N)$, basal area $(G)$, and stem volume $(V)$. Logarithmic transformations were used for $h \mathrm{~L}, N$, and $V$. For the models where spectral variables were selected, the alternative model (without spectral variables) was also reported.

\begin{tabular}{ccccccc}
\hline Dependent Variable & Predictive Model $^{\mathbf{a}}$ & Adj. $^{\mathbf{2} \mathbf{b}}$ & RMSE $^{\mathbf{b}}$ & Relative RMSE $^{\mathbf{b}}$ & $\overline{\mathbf{D}}^{\mathbf{b}}$ & Relative $^{\mathbf{b}}$ \\
\hline $\ln \left(h_{\mathrm{L}}\right)$ & $p_{30}+h_{\mathrm{sd}}$ & 0.68 & 1.55 & 13.66 & 0.01 & 0.13 \\
$\ln \left(h_{\mathrm{L}}\right)$ & $p_{20}+h_{\mathrm{sd}}+G_{\mathrm{m}}$ & 0.71 & 1.51 & 13.28 & 0.00 & 0.03 \\
$h_{\mathrm{dom}}$ & $p_{50}+h_{\mathrm{sd}}+d_{7}$ & 0.96 & 0.72 & 3.64 & 0.01 & 0.05 \\
$h_{\mathrm{dom}}$ & $p_{50}+h_{\mathrm{sd}}+d_{7}+G_{\mathrm{m}}$ & 0.97 & 0.69 & 3.48 & 0.01 & 0.04 \\
$\ln (N)$ & $p_{30}+d_{0}+d_{9}$ & 0.57 & 529.03 & 38.57 & -8.28 & -0.60 \\
$\ln (N)$ & $p_{30}+d_{0}+d_{9}+G_{\mathrm{sd}}$ & 0.60 & 538.31 & 39.24 & -4.90 & -0.36 \\
$G$ & $p_{100}+d_{0}+d_{9}$ & 0.60 & 4.49 & 15.38 & 0.03 & 0.09 \\
$\ln (V)$ & $p_{80}+d_{0}$ & 0.85 & 38.30 & 14.95 & 0.54 & 0.21 \\
\hline
\end{tabular}

${ }^{\mathrm{a}} p_{20}, p_{30}, p_{50}, p_{80}, p_{100}$ : percentiles of point heights for $20 \%, 30 \%, 50 \%, 80 \%$, and $100 \%(\mathrm{~m})$, respectively; $h_{\mathrm{sd}}$ : height standard deviation; $d_{0}, d_{7}, d_{9}$, canopy density corresponding to the proportions of points above fraction No. 1,8 , and 10 , respectively; $G_{\mathrm{m}}$ and $G_{\text {sd }}$ : respective mean and standard deviation of the green band; ${ }^{\mathrm{b}}$ Adj. $\mathrm{R}^{2}$ : adjusted $\mathrm{R}^{2}$; RMSE: root mean square error; relative RMSE: root mean square error as a percentage of the mean ground reference value; $\overline{\mathrm{D}}$ : mean difference; relative $\overline{\mathrm{D}}$ : mean difference as a percentage of the mean ground reference value.

Every model included only one height percentile. Different height percentiles were selected for each model; lower percentiles were adopted for $h_{\mathrm{L}}, h_{\mathrm{dom}}$, and $N\left(p_{20}, p_{50}\right.$, and $\left.p_{30}\right)$, while higher percentiles were selected for $G$ and $V$ ( $p_{100}$ and $p_{80}$, respectively). The standard deviation for height $\left(h_{\mathrm{sd}}\right)$ was also selected for the height models ( $h_{\mathrm{L}}$ and $h_{\mathrm{dom}}$ ). The density variables provided additional explanatory power in all of the models, except for $h_{\mathrm{L}}$. The extremes of the range ( $d_{1}$ and $\left.d_{9}\right)$ were generally selected, although $d_{7}$ was preferred for $h_{\mathrm{dom}}$. Spectral variables were selected for $h_{\mathrm{L}}, h_{\mathrm{dom}}$, and $N$. The green band was the only one selected, and the variables included were the mean value $\left(G_{\mathrm{m}}\right)$ and the standard deviation $\left(G_{\mathrm{sd}}\right)$. When these variables were omitted, the reduction in the adj. $\mathrm{R}^{2}$ was limited to $0.03,0.01$, and 0.03 for $h_{\mathrm{L}}, h_{\mathrm{dom}}$, and $N$, respectively. The analysis of the residuals revealed that all models had residuals that were normally distributed ( $p$-value $\geq 0.09$ ), with mean equal to zero ( $p$-value $\geq 1$ ), and with no serious problem of heteroscedasticity ( $p$-value $\geq 0.08$ ). 


\subsection{Plot-Level Validation}

The leave-one-out CV of the selected models revealed that the errors with respect to the RMSE for $h \mathrm{~L}, h_{\text {dom, }} G$, and $V$ were limited to $1.5 \mathrm{~m}(13.3 \%), 0.7 \mathrm{~m}(3.6 \%), 4.5 \mathrm{~m}^{2} \cdot \mathrm{ha}^{-1}(15.4 \%)$, and $38.3 \mathrm{~m}^{3} \cdot \mathrm{ha}^{-1}$ (14.9\%), respectively (Table 3). The error was larger for stem number, for which the RMSE was $538.3 \mathrm{ha}^{-1}(39.2 \%)$. All the models were affected by a limited mean difference, which in all cases had an absolute value that was equal to or smaller than $0.36 \%$ of the ground reference value. The CV of the models without spectral variables showed an increase in RMSE for $h \mathrm{~L}(0.04 \mathrm{~m} ; 0.4 \%)$ and $h$ dom $(0.03 \mathrm{~m}$; $0.2 \%)$, and a decrease for $N\left(-9\right.$ trees $\left.\cdot \mathrm{ha}^{-1} ;-0.7 \%\right)$. The reduction in $\overline{\mathrm{D}}$ was $0.01 \mathrm{~m}(0.1 \%)$ for $h \mathrm{~L}$, $0.001 \mathrm{~m}(0.01 \%)$ for $h_{\mathrm{dom}}$, and 3.38 trees $\cdot \mathrm{ha}^{-1}(-0.2 \%)$ for $N$. The two-sided t-test revealed that there were no significant differences $(p \geq 0.9)$ between the mean of the $\mathrm{CV}$ predicted and reference values for all of the models. Scatterplots of the observed versus predicted values for all variables from the cross validation is shown in Figure 4 for the selected models.
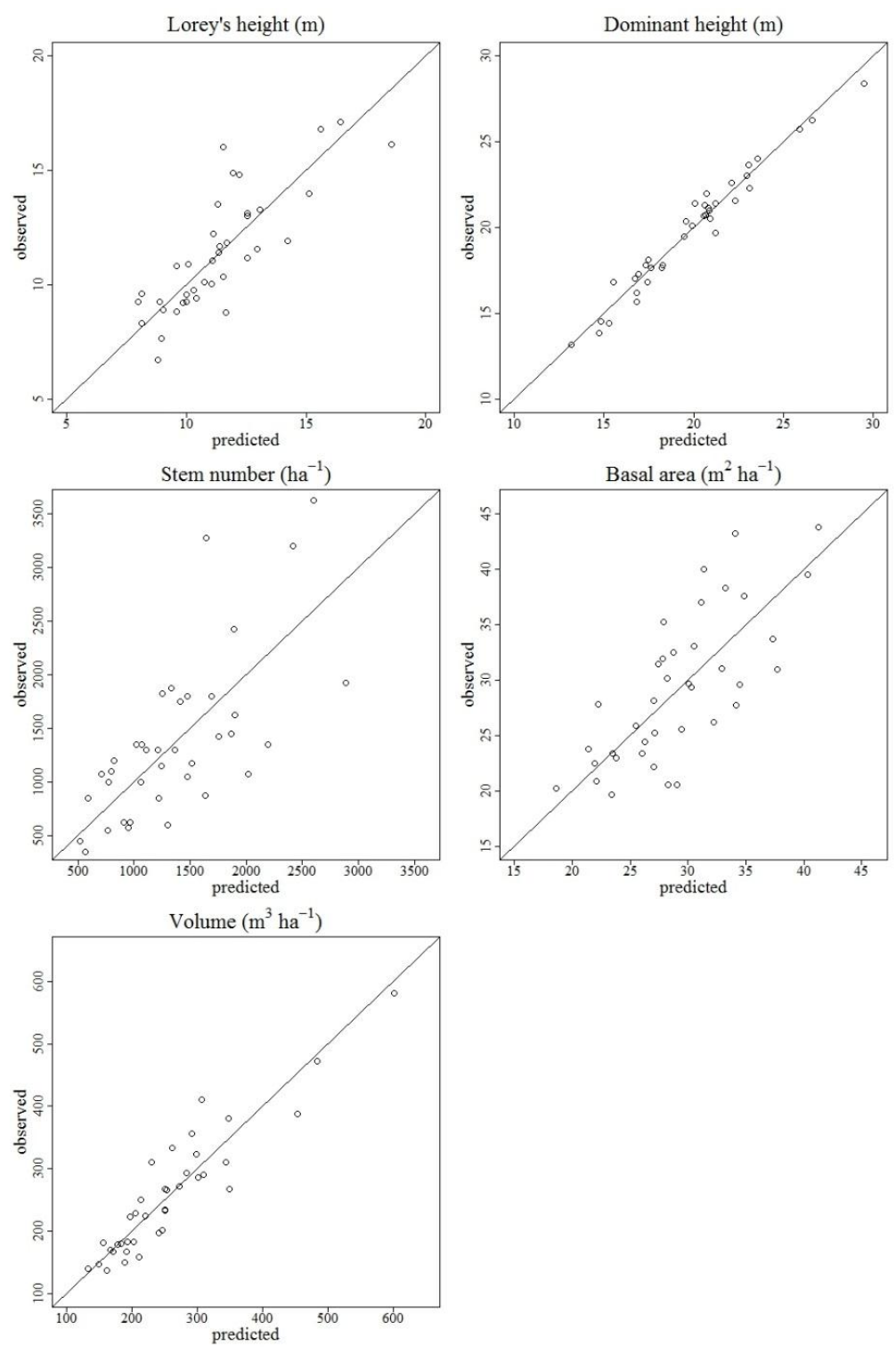

Figure 4. Scatterplot of observed versus predicted values from the cross validation for the models, including height, density, and spectral variables. 


\section{Discussion}

\subsection{UAS-SfM Forest Inventory Accuracy}

The results of the current study demonstrated that except for $N$ and $G$, the fitted models showed a rather good fit with an adj. $\mathrm{R}^{2}$ that was consistently higher than 0.71 . The cross-validated predictions at the plot level also proved the models to be reasonably accurate in terms of RMSE (i.e., relative RMSE $\leq 15.4 \%$ ) except for $\mathrm{N}$ (i.e., relative RMSE: 39.2\%). For all of the models, the mean differences between the predicted values and the field data were consistently small, with an absolute relative $\overline{\mathrm{D}}$ value that was smaller than $0.36 \%$. The $h_{\text {dom }}$ model yielded the most accurate predictions, followed by the $h_{\mathrm{L}}, V, G$, and $N$ models. The analysis of the residuals revealed no serious violation of the model assumptions. As previous studies have demonstrated, the stem number models were affected by larger errors, and $N$ was underestimated in plots with very dense forest. Due to the lack of stand reference data, no independent validation was carried out. Nevertheless, an improvement in accuracy can be expected when predicting at a stand level due to the averaging of the predictions over several prediction units or grid cells [57].

The results of the current study are consistent with previous studies using either ALS or photogrammetric data acquired from manned aircraft or UASs. In fact, the studied forest area was previously subjected to a comparative study carried out using ALS and manned airborne photogrammetric data [31]. Regardless of the fact that Gobakken et al. [31] inventoried a larger area using stratum-specific models, their results provide a base for comparison between manned airborne and UAS-borne data. Compared with the results of previous studies conducted in the same area but at a larger scale using ALS or Ultracam XP data [31,54], the main differences are that the current study shows that the $h_{\text {dom }}$ model had a higher adj. $\mathrm{R}^{2}$ value $(0.97)$ than that obtained for the $V$ model $(0.85)$, and the $G$ model had the smallest amount of explained variability among all of the models except for the $N$ model. The leave-one-out CV at a plot level showed that in terms of the RMSE, the accuracy of all of the models was of a similar magnitude as previous studies using ALS [54] or photogrammetric data [31]. When Gobakken et al. [31] used 7.4 points $\cdot \mathrm{m}^{-2}$ ALS data, the average relative RMSE values at the plot level ( $h \mathrm{~L}: 7.0 \% ; h_{\text {dom: }} 7.4 \% ; N: 31.0 \% ; G: 13.1 \% ; V: 14.3 \%$ ) were slightly smaller for all biophysical properties

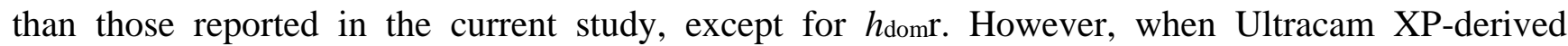
photogrammetric data were used to fit the models, the reported relative RMSEs [31] $\left(h_{\mathrm{L}}: 8.6 \% ; h_{\mathrm{dom}}: 8.2 \%\right.$; $N: 37.5 \% ; G: 16.3 \% ; V: 18.7 \%$ ) were larger than those in the current study, even for $h_{\text {dom, }} G$, and $V$. It is important to mention that some of the ground reference variables were estimated and therefore affected by errors. However, such limitation generally affects forest inventories, and the method used in the current study to estimate the mentioned variables was the same as the one used in Gobakken et al. [31], and therefore provided a valid basis for comparison.

Previous UAS-SfM studies in forest inventories [4,9,21] provide limited opportunities for comparisons because only dominant height was evaluated. These studies were conducted in temperate broadleaved forests, and the findings might not be transferable to boreal conditions. As expected for boreal conditions, the present study yielded higher $\mathrm{R}^{2}$ and lower RMSE values than previous studies. Both studies conducted by Dandois and Ellis $[9,21]$ revealed smaller $\mathrm{R}^{2}$ values $(0.07-0.84)$ and larger RMSEs (2.9-6.8 m) for $h_{\text {dom }}$ compared with the present study. The results obtained by Lisein et al. [4] were encouraging when implemented in an ABA ( $\mathrm{R}^{2}$ : 0.82; RMSE: $1.65 \mathrm{~m}$; relative RMSE: 8.4\%), and 
used in the individual tree crown approach ( $\mathrm{R}^{2}$ : 0.91; RMSE: $1.04 \mathrm{~m}$; relative RMSE: 4.7\%). Nevertheless, in the current study, the RMSE for the $h_{\text {dom }}$ model was $34 \mathrm{~cm}$ smaller than the best value reported by Lisein et al. [4]. The differences in the results from the current and previous studies likely lie in the variation of the surveyed forest types, flight configurations, and image acquisition. Boreal forests are typically more simple forest types in terms of species composition and height variations compared with temperate broadleaved forests, resulting in higher accuracy in remote-sensing based forest inventories. Additionally, differences in the flight settings (i.e., flight altitude, overlap, and ground sampling distance), number of GCPs, and accuracy of GCPs can partly explain the differences, as these parameters directly affect the quality of the 3D models generated from UAS imagery. Furthermore, the rapid development in UAS technology and advances in SfM algorithms have possibly played a role in reconstructing more accurate 3D geometries than in the past. Finally, the current study was carried out over relatively flat terrain; larger errors are expected in more mountainous areas due to difficulties in performing UAS flights on steep terrain, and larger errors are usually associated with the ALS DTM.

\subsection{Importance of Spectral Variables}

The comparison of models, including all variables without spectral information, revealed little improvements in terms of adj. $\mathrm{R}^{2}, \mathrm{RMSE}$, and $\overline{\mathrm{D}}$. The selected spectral variables for the $h_{\mathrm{L}}, h_{\mathrm{dom}}$, and $N$ models were the mean value and standard deviation of the green band. The limited improvement on the use of spectral variables over the structural variables is possibly attributable to the time of the year when the UAS imagery acquisition was carried out, the camera used, and the intrinsic issues related to UAS-SfM. The late fall acquisition influenced the image quality due to the effects of saturation, blurriness, low spectral response of the vegetation, absence of leaves for deciduous species, and presence of snow on part of the canopy. The effect of saturation was present because the images were acquired over a landscape composed of dark forests alternated with snow patches. The large contrast of the scene often led to the saturation of the camera detectors, resulting in either dark forests or bright snow. Wind speeds of up to $7 \mathrm{~m} \cdot \mathrm{sec}^{-1}$ caused blurriness, and the presence of snowflakes in some of the images further decreased the image quality. User-grade cameras are often characterized by poorer image quality than traditional aerial cameras due to poor calibration of the spectral response curve, vignetting, chromatic aberration, and incorrect color balancing [58]. UAS-SfM acquisitions over extensive areas larger than a single flight block are characterized by differences in the spectral response due to different light and atmospheric conditions during different flights. This resulted in a lack of consistency of the spectral response across the study area, causing increased noise to be included in the spectral variables. In contrast to previous research that indicated the red and near-infrared as the most relevant bands for vegetation mapping, this study found that the green band was the only relevant one. A potential explanation for this finding lies in the low spectral resolution of the camera sensor in the NIR and red bands; however, due to the proprietary nature of the hardware, no information was available to further investigate the issue.

Deeper understanding is therefore needed of the use of spectral data from UAS imagery to understand optimal timing during the year for image acquisition. As a matter of fact, acquiring imagery during the vegetative season may increase the information on the vegetation spectral component, and reduce some of the mentioned negative aspects related to the fall acquisition. This could potentially result in an 
increase in the accuracy of the model predictions and in the use of the spectral data acquired at specific phenological points in time to discriminate between tree species, allowing for species-specific forest inventories. Another issue worth mentioning is the determination of the best methods to assign color information to the generated 3D point clouds.

\subsection{General Considerations}

One of the main limitations of the present study for the operational application of UAS-SfM in forest inventories was the inefficiency of the UAS-SfM data acquisition in terms of daily coverage area (i.e., approximately 48 ha) due to the limited number of flights (i.e., on average: three flights day $^{-1}$ ) and the limited coverage of each flight (i.e., on average: $16.2 \mathrm{ha}$ ). The combined effect of the short amount of daylight available for image acquisition at high latitudes (approximately 4 hours) during late autumn, the adverse weather conditions, and the lack of battery power, which was exacerbated by higher battery consumption at low temperatures (i.e., approximately $0{ }^{\circ} \mathrm{C}$ ), contributed to a reduction in the number of flights. The limited coverage of each flight was a result of the short UAS battery life in cold temperatures, legislative constraints, and the need to acquire imagery with very large lateral overlaps. The European and national Remotely Piloted Aircraft Systems (RPAS) regulations are currently in a development phase, and in the future, airspace limitations for operators of small UASs (maximum $2.5 \mathrm{~kg}$ ) are likely to be similar to those used in the present study (i.e., max flight altitude: $120 \mathrm{~m}$ above ground level; working area radius: $600 \mathrm{~m}$ ). The reduction in the lateral overlap is highly dependent on improvements in the UAS firmware, specifically in the reduction of camera triggering rates, to achieve larger longitudinal overlaps. In this context, at the expense of a lower coverage area, multirotor platforms enable more accurate control of the longitudinal overlaps due to lower flying speeds.

Furthermore, additional improvements in the effectiveness of the data collection can be achieved by reducing the number of sample plots, reducing the number of GCPs, and increasing the experience of the operator. The development of a new generation of UAS equipped with GPS devices allowing for real time kinematic corrections is expected to have a large impact on the reduction of the amount of field work due to the elimination the GCPs. The present study proved that the issues related to the small coverage area and the poor spectral response of the vegetation arise when acquiring UAS imagery during late autumn at high latitudes, suggesting that a larger coverage area and more accurate results can be expected from UAS leaf-on imagery. Additionally, our study highlighted the need to acquire an adequate number of battery packs in relation to the time of the year when the UAS imagery acquisition is planned. It follows that more studies are required to define the optimal acquisition parameters, compare datasets acquired in different seasons, and validate results at different scales (i.e., plot and stand level) for operational UAS-SfM in forest inventories.

Regardless of the mentioned limitations, the study showed that is possible to successfully perform UAS-SfM forest surveys under varying weather conditions, including full cloud cover with wind speeds up to $7 \mathrm{~m} \cdot \mathrm{sec}^{-1}$, and occasional precipitation in the form of snow. This illustrates that UASs have a greater degree of planning flexibility and a longer season for imagery acquisition compared with traditional manned airborne imagery. In addition, the study showed that in approximately 15 days, it was possible to conduct an inventory (i.e., data collection, processing, modeling, and validating) of a 200 ha forest, showing that UASs can rapidly provide forest managers with ready-to-use data. The adaptive 
planning, project customization, rapid implementation, supported by robust methodologies, and the accurate results may make UASs an effective tool to map forest properties.

\section{Conclusions}

The results of the current study indicated that in spite of intrinsic challenges in the use of UAS-SfM in forestry, the five studied biophysical properties could be determined using UAS-SfM data with an accuracy comparable to that obtained using other popular remotely sensed data, such as ALS. The availability of on-demand accurate forest inventory information allows forest managers (i.e., small private forest owners and industry) to rapidly access data to support dynamic forest planning at a small scale. The importance of the present study lies in the definition of the main parameters involved in the acquisition of UAS imagery in forest areas and in providing accurate values that are achieved in forest inventories in boreal forests. Nevertheless, more experiments should be carried in a variety of forest types to determine the validity of the defined parameters and the accuracy reported. Indeed, in complex forest types (i.e., dense tropical forests), the use of UAS-SfM could be challenging due to the lack of accurate DTM and the complexity of the forest structure. In such cases, UAS-LS could provide a more appropriate solution for forest monitoring. It follows that a comparison of the two systems would be needed for a clear evaluation of the potential use of UASs for forest inventory purposes. These results are encouraging for the use of UASs in forest inventories; however, the effectiveness of UAS-SfM-based forest inventories should be evaluated by an analysis of the cost and benefits to determine the value of information from these types of inventories. The present study represented a pilot study case; providing a cost estimation would be misleading because improvements are likely to take place in the future with respect to the time involved in the inventory. Our findings also revealed that the models where spectral variables were included improved the prediction accuracy only to a limited degree, suggesting that more efforts should be invested to effectively exploit the spectral information contained in the imagery.

Future UAS-SfM forest inventory studies should aim to define the optimal application niches for which the value of the information derived from a very high spatial and temporal resolution forest survey would justify the costs.

\section{Acknowledgments}

We thank Blom Geomatics As for collecting and processing the airborne laser scanner data. We are also grateful to Ole Martin Bollandsås for processing the GPCs and base station files, and for providing valuable comments.

\section{Author Contributions}

Stefano Puliti was the main author of the manuscript, designed the study with the co-authors, carried out and supervised the fieldwork, and performed all data processing. Hans Ole Ørka, contributed with ideas and with the planning of remote sensing data acquisition. Terje Gobakken and Erik Næsset co-authored and revised the manuscript. 


\section{Conflicts of Interest}

The authors declare no conflicts of interest.

\section{References}

1. Wallace, L.; Lucieer, A.; Watson, C.; Turner, D. Development of a UAV-LiDAR system with application to forest inventory. Remote Sens. 2012, 4, 1519-1543.

2. Whitehead, K.; Hugenholtz, C.H. Remote sensing of the environment with small unmanned aircraft systems (UASs), part 1: A review of progress and challenges. J. Unmanned Veh. Syst. 2014, 2, 69-85.

3. Andersen, H.E.; Reutebuch, S.E.; McGaughey, R.J. A rigorous assessment of tree height measurements obtained using airborne lidar and conventional field methods. Can. J. Remote Sens. 2006, 32, 355-366.

4. Lisein, J.; Pierrot-Deseilligny, M.; Bonnet, S.; Lejeune, P. A photogrammetric workflow for the creation of a forest canopy height model from small unmanned aerial system imagery. Forests 2013, 4, 922-944.

5. Whitehead, K.; Hugenholtz, C.H.; Myshak, S.; Brown, O.; LeClair, A.; Tamminga, A.; Barchyn, T.E.; Moorman, B.; Eaton, B. Remote sensing of the environment with small unmanned aircraft systems (UASs), part 2: Scientific and commercial applications. J. Unmanned Veh. Syst. 2014, 2, 86-102.

6. Paneque-Gálvez, J.; McCall, M.; Napoletano, B.; Wich, S.; Koh, L. Small drones for community-based forest monitoring: An assessment of their feasibility and potential in tropical areas. Forests 2014, 5, 1481-1507.

7. Nex, F.; Remondino, F. UAV for 3D mapping applications: A review. Appl. Geomat. 2014, 6, 1-15.

8. Salamí, E.; Barrado, C.; Pastor, E. UAV flight experiments applied to the remote sensing of vegetated areas. Remote Sens. 2014, 6, 11051-11081.

9. Dandois, J.P.; Ellis, E.C. High spatial resolution three-dimensional mapping of vegetation spectral dynamics using computer vision. Remote Sens. Environ. 2013, 136, 259-276.

10. Hugenholtz, C.H.; Moorman, B.J.; Riddell, K.; Whitehead, K. Small unmanned aircraft systems for remote sensing and earth science research. Eos. Trans. Am. Geophys. Union 2012, 93, 236.

11. Watts, A.C.; Ambrosia, V.G.; Hinkley, E.A. Unmanned aircraft systems in remote sensing and scientific research: Classification and considerations of use. Remote Sens. 2012, 4, 1671-1692.

12. Næsset, E. Airborne laser scanning as a method in operational forest inventory: Status of accuracy assessments accomplished in Scandinavia. Scand. J. For. Res. 2007, 22, 433-442.

13. Vauhkonen, J.; Maltamo, M.; McRoberts, R.E.; Næsset, E. Introduction to forestry applications of airborne laser scanning. In Forestry Applications of Airborne Laser Scanning; Maltamo, M., Næsset, E., Vauhkonen, J., Eds; Springer: Dordrecht, The Netherlands, 2014; pp. 1-16.

14. Wallace, L.; Musk, R.; Lucieer, A. An assessment of the repeatability of automatic forest inventory metrics derived from UAV-Borne laser scanning data. IEEE Trans Geosci. Remote Sens. 2014, 52 , 7160-7169.

15. Jaakkola, A.; Hyyppä, J.; Kukko, A.; Yu, X.; Kaartinen, H.; Lehtomäki, M.; Lin, Y. A low-cost multi-sensoral mobile mapping system and its feasibility for tree measurements. ISPRS J. Photogramm. Remote Sens. 2010, 65, 514-522. 
16. Wallace, L.; Lucieer, A.; Watson, C.S. Evaluating tree detection and segmentation routines on very high resolution UAV LiDAR data. IEEE Trans Geosci. Remote Sens. 2014, 52, 7619-7628.

17. Wallace, L.; Watson, C.; Lucieer, A. Detecting pruning of individual stems using airborne laser scanning data captured from an unmanned aerial vehicle. Int. J. Appl. Earth Obs. Geoinf. 2014, $30,76-85$.

18. Chisholm, R.A.; Cui, J.; Lum, S.K.Y.; Chen, B.M. UAV LiDAR for below-canopy forest surveys. J. Unmanned Veh. Sys. 2013, 1, 61-68.

19. Aber, J.S.; Sobieski, R.J.; Distler, D.A.; Nowak, M.C. Kite aerial photography for environmental site investigations in Kansas. Trans. Kansas Acad. Sci. 1999, 102, 57-67.

20. Dunford, R.; Michel, K.; Gagnage, M.; Piégay, H.; Trémelo, M.L. Potential and constraints of unmanned aerial vehicle technology for the characterization of Mediterranean riparian forest. Int. J. Remote Sens. 2009, 30, 4915-4935.

21. Dandois, J.P.; Ellis, E.C. Remote sensing of vegetation structure using computer vision. Remote Sens. 2010, 2, 1157-1176.

22. Colomina, I.; Molina, P. Unmanned aerial systems for photogrammetry and remote sensing: A review. ISPRS J. Photogramm. Remote Sens. 2014, 92, 79-97.

23. Wang, T.; Yan, L.; Mooney, P. Dense point cloud extraction from UAV captured images in forest area. In Proceedings of the 2011 IEEE International Conference on Spatial Data Mining and Geographical Knowledge Services (ICSDM), Fuzhou, China, 29 June-1 July 2011.

24. Gini, R.; Passoni, D.; Pinto, L.; Sona, G. Aerial images from an UAV system: 3D modeling and tree species classification in a park area. Int. Arch. Photogramm. Remote Sens. Spatial Inf. Sci. 2012, 39, 361-366.

25. Fritz, A.; Kattenborn, T.; Koch, B. UAV-based photogrammetric point clouds-Tree stem mapping in open stands in comparison to terrestrial laser scanner point clouds. Int. Arch. Photogramm. Remote Sens. Spat. Inf. Sci. 2013, 40, 141-146.

26. Imagine Games Network. MICMAC Software for Automatic Mapping in Geographical Context. Available online: http://logiciels.ign.fr/?Micmac (accessed on 7 March 2015).

27. Trimble. Trimble Unmanned Aircraft Systems for Surveying and Mapping. Available online: http://uas.trimble.com/sites/default/files/downloads/trimble_uas_brochure_english.pdf (accessed on 7 March 2015).

28. Packalen, P.; Strunk, J.; Mehtätalo, L.; Maltamo, M. Resolution Dependence in an area-based approach to forest inventory with ALS. Available online: http://ocs.agr.unifi.it/index.php/ forestsat2014/ForestSAT2014/paper/view/387 (accessed on 15 June 2015).

29. Sperlich, M.; Kattenborn, T.; Koch, B. Potential of Unmanned Aerial Vehicle Based Photogrammetric Point Clouds for Automatic Single Tree Detection. Available onlilne: http://www.dgpf.de/neu/ Proc2014/proceedings/papers/Beitrag270.pdf (accessed on 15 January 2015).

30. Bohlin, J.; Wallerman, J.; Fransson, J.E.S. Forest variable estimation using photogrammetric matching of digital aerial images in combination with a high-resolution DEM. Scand. J. For. Res. 2012, 27, 692-699.

31. Gobakken, T.; Bollandsås, O.M.; Næsset, E. Comparing biophysical forest characteristics estimated from photogrammetric matching of aerial images and airborne laser scanning data. Scand. J. For. Res. 2014, 30, 1-37. 
32. Daamen, W. Results from a Check on Data Collection of the National Forest Survey in 1973-1977; Umeå: Institutionen för skogstaxering, Sveriges lantbruksuniversitet: Uppsala, Sweden, 1980; p. 189. (in Swedish).

33. Eriksson, H. On Measuring Errors in Tree Height Determination with Different Altimeters; Stockholm Skogshögskolan, Institutionen för skogsproduktion: Stockholm, Sweden, 1970. (in Swedish).

34. Fitje, A.; Vestjordet, E. Stand height curves and new tariff tables for Norway spruce. Commun. Nor. For. Res. Inst. 1977, 34, 23-62.

35. Vestjordet, E. Merchantable volume of Norway spruce and Scots pine based on relative height and diameter at breast height or $2.5 \mathrm{~m}$ above stump level. Medd. Det Nor. Skogfors $\phi$ ksves. 1968, 25, 411-459. (in Norwegian)

36. Braastad, H. Volume tables for birch. Medd. Nor. SkogforsVes 1966, 21, 23-78. (in Norwegian)

37. Brantseg, A. Volume functions and tables for Scots pine. South Norway. Medd. Nor. SkogforsVes 1967, 22, 689-739. (in Norwegian).

38. Vestjordet, E. Functions and tables for volume of standing trees. Norway spruce. Medd. Nor. Skogfors Ves 1967, 22, 539-574. (in Norwegian).

39. Terrasolid. TerraScan User' s Guide. Available online: http://www.terrasolid.com/download/tscan.pdf (accessed on 17 July 2015).

40. SenseFly. eBee Extended User Manual. Available online: https://www.sensefly.com/fileadmin/ user_upload/documents/manuals/Extended_User_Manual_eBee_and_eBee_Ag_v16.pdf (accessed on 20 April 2015).

41. SenseFly. User Manual S110 RGB/NIR/RE Camera. Available online: https://www.sensefly.com/ fileadmin/user_upload/documents/manuals/user_manual_s110_v3.pdf (accessed on 15 November 2014).

42. SenseFly. eMotion: Release Notes. Available online: https://www.sensefly.com/fileadmin/user_upload/ documents/release_notes/Release_Notes_2.4.5.pdf (accessed on 15 April 2015).

43. Quantum GIS Geographic Information System. Open Source Geospatial Foundation Project. Available online: http://www.qgis.org/it/site/ (accessed on 1 September 2014).

44. Etterprosessering med Pinnacle. Available online: http://www.blinken.no/gnss-program.htm (accessed on 15 April 2015).

45. Agisoft. Agisoft Photoscan User Manual. Available online: http://www.agisoft.com/pdf/photoscanpro_1_1_en.pdf (accessed on 6 February 2015).

46. Verhoeven, G.; Doneus, M.; Briese, C.; Vermeulen, F. Mapping by matching: a computer vision-based approach to fast and accurate georeferencing of archaeological aerial photographs. J. Archaeol. Sci. 2012, 39, 2060-2070.

47. Agisoft. Tutorial (Beginner level): Orthophoto and DEM Generation with Agisoft PhotoScan Pro 1.1 (with Ground Control Points). Available online: http://www.agisoft.com/pdf/PS_1.1\%20-Tutorial\% 20(BL)\%20-\%20Orthophoto,\%20DEM\%20(with\%20GCP).pdf (accessed on 6 February 2015)

48. Yu, B.; Member, S.; Ostland, I.M.; Gong, P.; Pu, R. Penalized discriminant analysis of in situ hyperspectral data for conifer species recognition. IEEE Trans. Geosci. Remote Sens. 1999, 35, 2569-2577.

49. Wu, C. Normalized spectral mixture analysis for monitoring urban composition using ETM+ imagery. Remote Sens. Environ. 2004, 93, 480-492. 
50. Dalponte, M.; Orka, H.O.; Gobakken, T.; Gianelle, D.; Næsset, E. Tree species classification in boreal forests with hyperspectral data. IEEE Trans Geosci. Remote Sens. 2013, 51, 2632-2645.

51. Dalponte, M.; Ørka, H.O.; Ene, L.T.; Gobakken, T.; Næsset, E. Tree crown delineation and tree species classification in boreal forests using hyperspectral and ALS data. Remote Sens. Environ. 2014, 140, 306-317.

52. Næsset, E. Practical large-scale forest stand inventory using a small-footprint airborne scanning laser. Scand. J. For. Res. 2004, 19, 164-179.

53. Nilsson, M. Estimation of tree heights and stand volume using an airborne lidar system. Remote Sens. Environ. 1996, 56:1-7.

54. Næsset, E. Predicting forest stand characteristics with airborne scanning laser using a practical two-stage procedure and field data. Remote Sens. Environ. 2002, 80, 88-99.

55. Lumley, T.; Miller, A. Package "Leaps": Regression Subset Selection. Available online: http://cran.rproject.org/web/packages/leaps/leaps.pdf (accessed on 2 June 2014).

56. Snowdon, P. A ratio estimator for bias correction in logarithmic regressions. Canad. J. For. Res. 1991, 21, 720-724.

57. Gobakken, T.; Næsset, E. Estimation of diameter and basal area distributions in coniferous forest by means of airborne laser scanner data. Scand. J. For. Res. 2004, 19, 529-542.

58. Hakala, T.; Suomalainen, J.; Peltoniemi, J.I. Acquisition of bidirectional reflectance factor dataset using a micro unmanned aerial vehicle and a consumer camera. Remote Sens. 2010, 2, 819-832.

(C) 2015 by the authors; licensee MDPI, Basel, Switzerland. This article is an open access article distributed under the terms and conditions of the Creative Commons Attribution license (http://creativecommons.org/licenses/by/4.0/). 